\title{
Enhanced Chemical Oxygen Demand Removal in the Pre-Treatment of Sludge Wastewater by Coagulation
}

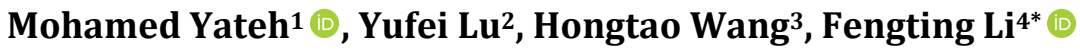 \\ ${ }^{1}$ College of Environmental Science and Engineering, UNEP-Tongji Institute of Environment for Sustainable Development, Tongji \\ University, Shanghai, China \\ ${ }^{2}$ Shanghai CEO Environmental Protection Technology Co., Ltd., Shanghai, China \\ ${ }^{3}$ Key Laboratory of Yangtze River Water Environment, Ministry of Education, State Key Laboratory of Pollution Control and \\ Resource Reuse, College of Environmental Science and Engineering, Tongji University, Shanghai, China \\ ${ }^{4}$ UN Environment-Tongji Institute of Environment for Sustainable Development, Key Laboratory of Cities Mitigation and \\ Adaptation to Climate Change, College of Environmental Science and Engineering, Tongji University, Shanghai, China \\ Email: yatmed01@yahoo.com, luyufei@ceo.sh, hongtao@tongji.edu.cn, ^fengting@tongji.edu.cn
}

How to cite this paper: Yateh, M., Lu, Y.F., Wang, H.T. and Li, F.T. (2020) Enhanced Chemical Oxygen Demand Removal in the Pre-Treatment of Sludge Wastewater by Coagulation. Open Access Library Journal, 7: e6948.

https://doi.org/10.4236/oalib.1106948

Received: October 29, 2020

Accepted: November 27, 2020

Published: November 30, 2020

Copyright ( 2020 by author(s) and Open Access Library Inc.

This work is licensed under the Creative Commons Attribution International License (CC BY 4.0).

http://creativecommons.org/licenses/by/4.0/

(c) (i) Open Access

\begin{abstract}
At present, a cost-effective selection of parameters for Chemical Oxygen Demand (COD) and turbidity reduction is of great importance for wastewater treatment. Like most water treatment processes, the coagulation treatment process may sound simple but is considered as an important method for wastewater treatment as it helps to remove COD and other pollutants found in wastewater. Poly aluminum chloride (PAC) with Poly ammonia (PA) coagulants was used to study the performance of the coagulation process of sludge wastewater obtained after the dewatering process. A scanning Electron Microscope (SEM) machine was also used to compare the characteristic of the flocs produced after treatment. The influence of coagulant dosing and settling time characteristics of the flocs were examined. Based on the result, with the use of poly aluminum chloride, it shows a removal efficiency of $77.9 \%$ COD. Furthermore, with the addition of Poly ammonia (PA), a greater efficiency removal of $80.6 \%$ of COD was obtained with higher turbidity removal and better flocs cohesion. Results also indicate that varying other treatment parameters like $\mathrm{pH}$ and temperature for effective pre-treatment have little or no significant effect on COD as well as turbidity removal.
\end{abstract}

\section{Subject Areas}

Water and Environmental Engineering

\section{Keywords}

Chemical Oxygen Demand, Coagulation, Poly Aluminum Chloride, Poly 
Ammonia, Sludge Wastewater

\section{Introduction}

There has been a growing concern about the use of wastewater, it increased economic considerations and stringent environmental regulations for its discharged rate on the environment. This has highlighted the importance of finding efficient wastewater treatment parameters and management. As this issue is becoming a major concern, effective treatment should be carefully explored to know the most efficient ways of treating wastewater [1] [2] [3] [4] [5]. The presence of contaminants in wastewater signifies a threat to the environment and public health [6] [7] [8] of its inhabitants even at very low concentrations [3] [9]. Large volume of wastewater is usually generated during the sludge dewatering processes and the wastewater is generally strong and may contain large toxic pollutants [10] [11]. Its composition and characteristics are different from domestic water, as such pretreatment is required to reduce its devastating effect before being discharged into the environment.

Chemical Oxygen Demand (COD) is the amount of oxygen taken from the oxidant for chemical oxidation of organic matter and some inorganic compounds like nitrites, sulfates, etc. [9] [12]. The COD of sludge wastewater can vary ranging between 850 and $5000 \mathrm{mg} / \mathrm{L}$, it can also increase up to $15,000 \mathrm{mg} / \mathrm{L}$. The reduction of COD measures the effectiveness of the wastewater treatment process. Research has shown that traditional biological purification does not remove toxic compounds and the total content of organic compounds (like COD) [9] [13]. Therefore, it is imperative to apply other treatment processes to aid greater efficiency removal of toxicants in wastewater.

Different conventional treatment processes have been used to treat different wastewater [9] [14]. But due to the characteristics of the different wastewater and colloidal suspension, the particles do not normally sediment or separate with other conventional physical methods like as filtration, unless by the aid of other processes such as coagulation [4] [7] [8] [11] [15]. The application of this process to eliminate pollutants from wastewater supplies has been given great attention from industries around the world [16] [17] [18]. This is because the process has been considered as an effective and low-cost pre-treatment method [19] [20] for improving water quality parameters [21]. During coagulation process, often over $35 \%$ reduction is obtained for COD removal of nutrient-rich wastewater [22]. But, the basic procedural problem of this treatment process is the choice of the coagulant to use and the determination of its optimal dose.

Poly aluminum chloride (PAC) coagulants are extensively been used in potable and wastewater treatment plants [20] [23] as a result of its wide application in treatment processes [17] [24] [25] [26]. This is because it is perfect for bulk storage and can be stable for up to five months when stored at less than $50^{\circ} \mathrm{C}$ [23]. 
Another major benefit of using PAC has been a considerable reduction in the volumes of sludge trucked off-site to disposal. The volume of sludge hauled has had a major impact on plant operating cost [23]. Therefore, any potential application to minimize such cost is appreciable in the field of wastewater treatment.

Likewise, polymers are used in wastewater treatment to improve the efficiency of sludge thickening and dewatering, and in drinking water treatment as flocculants to remove suspended solid [5] [10]. This is as a result of their characteristics, concentration, molecular weight, nature and chemical composition in water treatment efficiency [26]. The present study aims to evaluate effective removal of COD in the pre-treatment of sludge wastewater generated after the dewatering process with different dosing conditions. The best approach to treat highly contaminated wastewater is to treat them at the source by applying onsite pre-treatment before applying other treatment processes [27].

\section{Materials and Method}

\subsection{Materials}

Chemical reagents used in this process as coagulants are Poly aluminum chloride (PAC) and Poly ammonia (PA) supplied by chemical industries as shown in Table 1. These coagulants are all of the technical grades and have been used for different water and wastewater treatment processes. The sludge came from a landfill that has stayed for five years. The samples were collected in the Bailong Gang factory in Baoshan district, Shanghai. From this sludge, they produced fertilizers which can be applied to agricultural cropland, or as biosolid compost for use in landscaping etc. Upon collection of the Sludge samples from the factory, it was preserved in a $25 \mathrm{~L}$ non-absorbing PVC container, and stored at normal room temperature $\left(23^{\circ} \mathrm{C} \pm 1^{\circ} \mathrm{C}\right)$ in the laboratory. The main physicochemical characteristics of the sludge wastewater obtained from the dewatering process are presented in Table 2. It illustrates the sludge sample was dark in color, turbid with a pH slightly higher than 7.0, and a high concentration of COD.

\subsection{Preparation of Stock Solutions (Weight/Volume \%)}

The standard solution of $1000 \mathrm{ppm}(1 \pm 0.005 \mathrm{~g} / \mathrm{L})$ and $50 \mathrm{ppm}(0.05 \pm 0.005$ $\mathrm{g} / \mathrm{L}$ ) of poly aluminum chloride and poly ammonia were weighed and prepared

Table 1. Chemical industries of experiment coagulants.

\begin{tabular}{cc}
\hline Coagulants & Supplier \\
\hline $\begin{array}{c}\text { Poly aluminum chloride } \\
\text { Poly ammonia }\end{array}$ & Hanyu water chemical, Jiangsu \\
Poly ferric sulfate & Wanshi environmental protection company, Shanghai \\
Decolorizer & Xintai water treatment chemicals, Shandong \\
Polymer Polyacrylamide & Wanshi environmental protection company, Shanghai \\
\hline
\end{tabular}


Table 2. Sludge wastewater characterization before/after pretreatment.

\begin{tabular}{cccc}
\hline Parameters & Sludge wastewater & Treated with PAC & $\begin{array}{r}\text { Treated with } \\
\text { PAC and PA }\end{array}$ \\
\hline $\mathrm{pH}$ & 7.63 & 7.12 & 7.09 \\
Temperature $\left({ }^{\circ} \mathrm{C}\right)$ & 23.8 & 22.6 & 23.5 \\
$\mathrm{COD}(\mathrm{mg} / \mathrm{L})$ & 934.6 & 201 & 181 \\
Turbidity $(\mathrm{NTU})$ & Too high & 62.2 & 40.6 \\
\hline
\end{tabular}

by diluting with distilled water in a $1000 \mathrm{~mL}$ flask. Thereafter, $12.5 \mathrm{ml}$ of PA were measured and transfer in a $500 \mathrm{~mL}$ flask to get the $50 \mathrm{ppm}$ solution, and then stored all solutions at room temperature.

\subsection{Experiment Set-Up}

This study was performed using dewatering pump, an SEM machine and coagulation process. The sludge wastewater obtained for the experiment was generated during the dewatering process by using Poly ferric sulfate, decolorizer, and Polymer Polyacrylamide coagulant. The sludge was treated with variable dosages of these coagulants having different doses ranging and using separatory funnels. The flocs were later collected after coagulation process, dried in an oven $\left(80^{\circ} \mathrm{C}\right)$ for one day and analyses the flocs sizes using the SEM machine.

To obtain a more effective range of considered treatment factors for the coagulation process, some preliminary trials with a wide and low coagulant dose of PAC and PA ranges of $0.95-30 \mathrm{ml}$ and $0.5-10 \mathrm{ml}$ were carried out before the experimental design respectively. Thereafter, the selected ranges of coagulant doses were between $10-20 \mathrm{ml}$ for PAC and $1-3.5 \mathrm{ml}$ for PA. The COD was first conducted with 25 experiments of COD vials of $2-1500 \mathrm{mg} / \mathrm{L}$. But, the levels of the COD range were too high in the spectrophotometer. As a result, high plus COD vials $(200-15,000 \mathrm{mg} / \mathrm{L})$ was used to determine the initial and final COD concentration of the treated wastewater samples. The study does not investigate the varying effect on $\mathrm{pH}$ and temperature values. The experimental results were performed with the origin Pro 8.0 software in this work. Figure 1 shows the treatment processes used in the study.

\subsection{Jar Test Procedure}

The Coagulation experiments were performed with a $\mathrm{HACH}$ jar test apparatus comprising five agitator rotors in $100 \mathrm{ml}$ beakers. A rapid mixing with a 400 $\mathrm{rev} / \mathrm{min}$ for one minute, a slow mixing speed of $100 \mathrm{rev} / \mathrm{min}$ for ten minutes and a settling time of flocs for 25 minutes was carried out. The supernatant from each beaker was taken out and tested for turbidity [28] through the $\mathrm{HACH}$ turbidimeter, and for $\mathrm{COD}$ using the $\mathrm{HACH}$ spectrophotometer. The treated wastewater $\mathrm{pH}$ and temperature were also measured using the $\mathrm{pH}$ meter. The experiments were duplicated two times. 


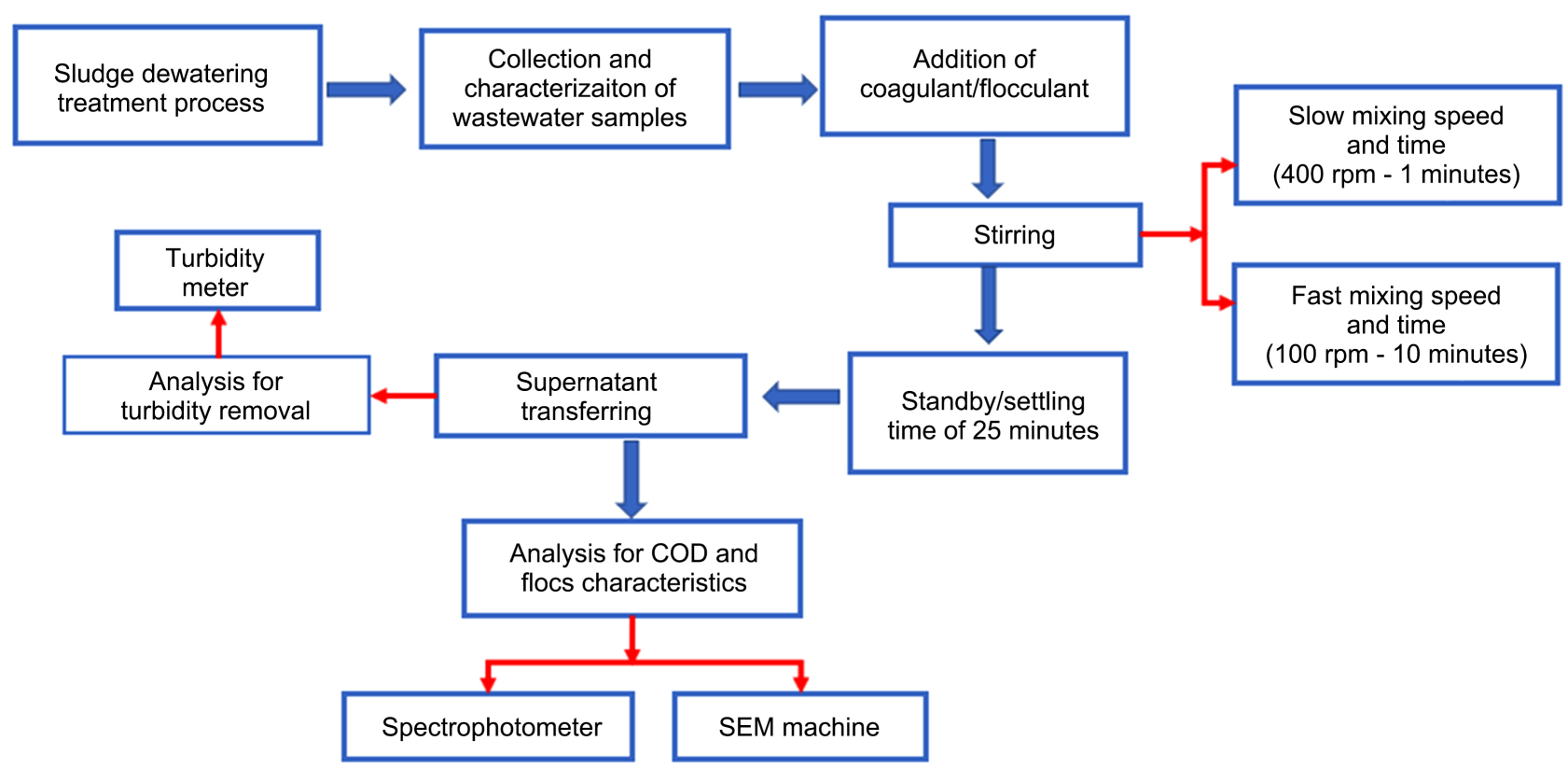

Figure 1. Schematic description of treatment processes used in the study.

\subsection{Scanning Electron Microscope (SEM) Method}

The SEM is a magnification tool that helps to describe the surface structure of materials [11]. A SEM machine was used to observed the flocs size characteristics [29] before and after treatment. This method was applied to obtain information about the flocs surface structure and composition. After collecting the supernatant from the selected beakers, the settled flocs at the bottom of each beakers were then transfer to a plastic tray which was then put in an $80^{\circ} \mathrm{C}$ oven and dried for one day. Thereafter, samples were collected, scraped-off, and placed in a pin mount sample holder attached with sticky conducting tape. Two samples were used for analysis, the one with no treatment chemical and other with the best coagulant dosages of PAC and PA. They were electrically connected to the sample holder to prevent the electron beam from "charging" the sample and distorting the image.

\subsection{Calculations}

The determination of the COD removal efficiency parameter was obtained using the following equation,

$$
\% \mathrm{COD}=\frac{\mathrm{Ei}-\mathrm{Ef}}{\mathrm{Ei}} \times 100 \%
$$

where;

$\%$ COD is the efficiency of COD removal,

Ei is the initial COD concentrations before treatment, and

$\mathrm{Ef}$ is the final COD concentrations after treatment.

\section{Results and Discussion}

The coagulation treatment process is subject to many factors that can affect its 
efficiency and operation [7] [17]. This work provides the account and reasons for the enhanced optimization of pre-treatment schemes for effective COD removal in wastewater treatment. The findings of this study have some significant suggestions for practice. The jar tests were conducted for a practical understanding of the selected treatment performance and to find optimum coagulant dosage for COD removal as well as turbidity from the generated wastewater. In this study, no wide/low range of $\mathrm{pH}$ and temperature were selected to process at the laboratory. This was done to determine which coagulant dosage can best be achieved to remove COD and turbidity without varying these parameters. The experimental results indicate that removal efficiencies of the coagulation treatment process are not only dependent on varying the wastewater $\mathrm{pH}$ and temperature [7] [15] [17] [30] but also selecting efficient mixing speed and time [28]. Poor mixing speed and time can fail to make an aggregation of the flocs to successfully coagulate the particles for efficient flocculation [17] [28].

\subsection{Effect of Coagulant Dosage on COD and Turbidity Removal}

As shown in Figure 2, both PAC and PA exhibited better removal performance for turbidity and COD. It was observed that the coagulation process for all the dosages decreases the selected parameters (COD and turbidity) of the wastewater. When using PAC only with dosages of $15 \mathrm{ml}$, a better efficiency removal of $70.8 \%$ of COD with turbidity of 79.5 NTU was observed. This clearly shows using PAC only was good in COD reduction but less efficient in turbidity removal. However, combinations of PA were carried out to determine which best pair can be used to further reduce the wastewater turbidity and COD. With the addition of PA and PAC, both coagulants show greater removal efficiencies as each coagulant dosage increased. The addition of $20 \mathrm{ml} \mathrm{PAC}$ and $3.5 \mathrm{ml} \mathrm{PA}$ reduced COD up to $80.6 \%$ with a turbidity of 40.6 NTU. The removal efficiency showed a sharp decline of COD as well as turbidity and better performance at this stage.

This further depict that removal efficiencies of turbidity might increase by increasing the dosages of both coagulants [17], but the concentration of the water samples will be higher which makes noncompliance with environmental regulation. In recognition of the importance to determine effective pre-treatment efficiency, the indicated parameters must be in connection with the socio-economic factors [5]. The selection of appropriate treatment parameters and technologies is one of the major challenges and significant factors that determines the further development of company, municipality or entire country treatment processes.

As shown (Figure 2), COD by $70.8 \%$ for PAC and $80.6 \%$ with combination of $\mathrm{PAC}$ and PA were removed respectively. This further show that the coagulation is a more efficient pre-treatment method that favors different conditions. According to the results, the COD concentration drop continued up to 201 and 311 $\mathrm{mg} / \mathrm{L}$ for PAC and 388 to $181 \mathrm{mg} / \mathrm{L}$ with the combination of PAC and PA respectively (Figure 3 ). Thus, the optimum dosage for the studied wastewater 
treatment was considered at $20 \mathrm{mg} / \mathrm{L}$ and $3.5 \mathrm{mg} / \mathrm{L} \mathrm{PAC} \mathrm{and} \mathrm{PA} \mathrm{respectively.} \mathrm{It}$ is suggested that application of higher coagulants dosage range may improve turbidity removal from the high turbidity wastewater. Both PA and PAC demonstrated promising performance in $\mathrm{COD}$ and turbidity removal from the produced wastewater.

In Figure 4, the working characteristics of the coagulants dosages used showed a different behavior that differs from another [30]. With the addition of $15 \mathrm{ml}$ PAC and $2.5 \mathrm{ml}$ Poly ammonia, the value of 21.5 NTU turbidity reduction of the wastewater was outstanding compared to the other dosages. However, the removal efficiency of COD was not that significant as only $47.5 \%$ was achieved compared to other additions. This addition shows better efficiency of turbidity. In general, these coagulant dosages addition could not increase COD removal

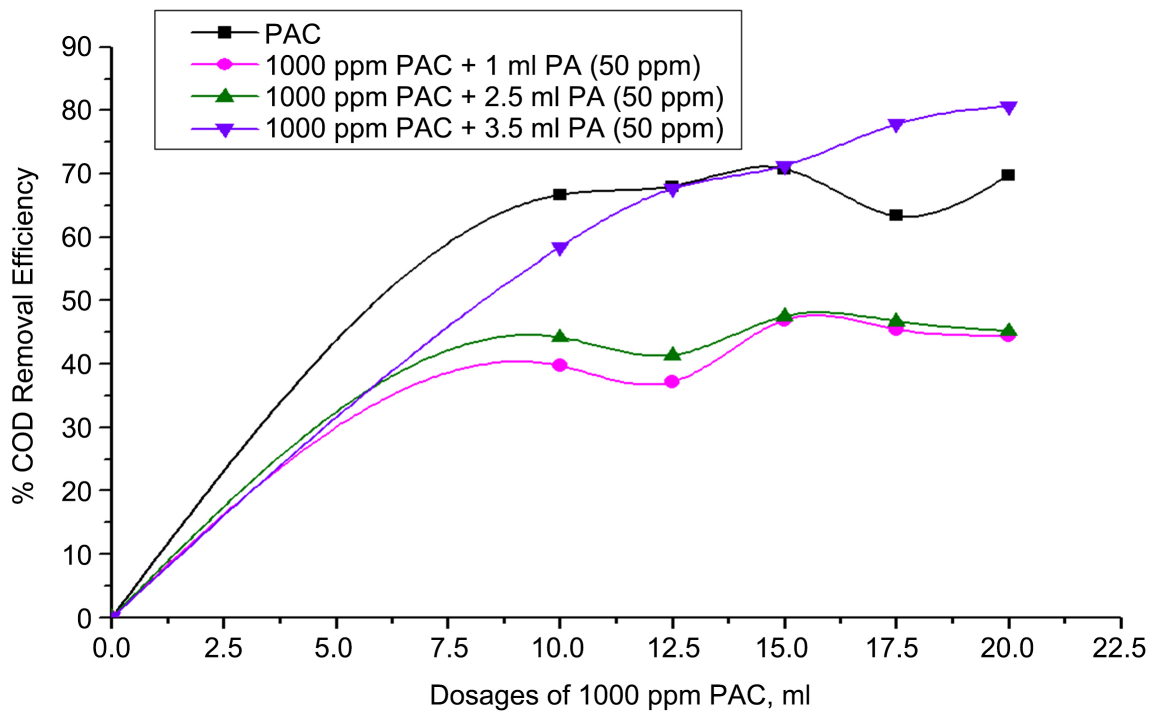

Figure 2. Variation of COD removal efficiency.

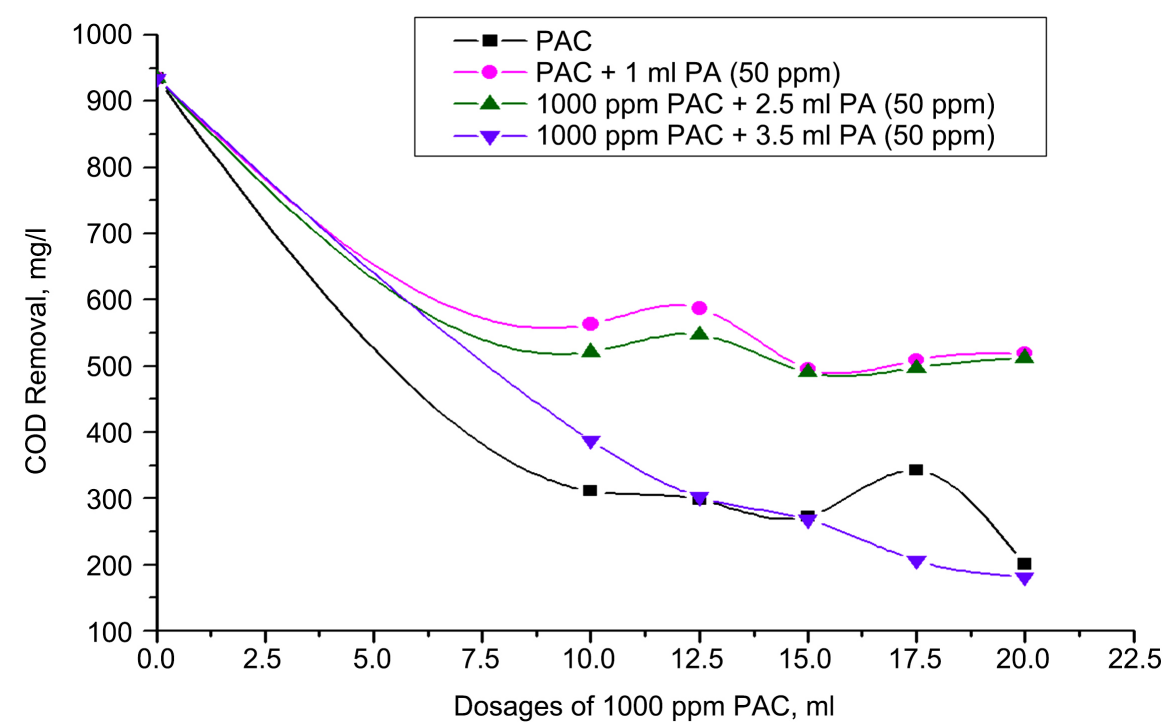

Figure 3. COD removal with PAC and combination of PA. 


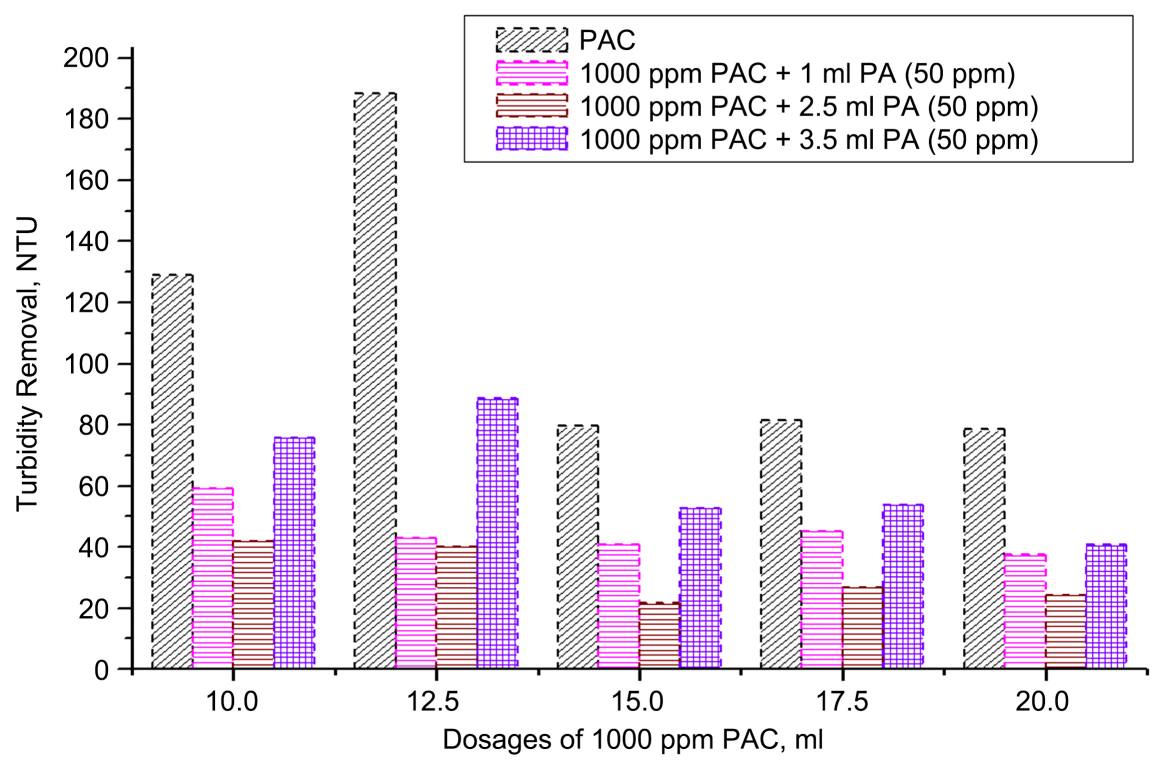

Figure 4. Variation of turbidity removal efficiency.

efficiency, but rather increase turbidity removal efficiency considerably. In most cases, flocculant application improved coagulation process to some extent; this reduction may be attributed to charge reversal and re-stabilization of colloidal particles [17].

\subsection{Flocs Size}

The composition of the flocs produced during the treatment of the wastewater samples as determined by the Scanning electron microscopes (SEM) machine is shown in Figures 6(a)-(d). The black and white surface shown in the figures represents the surface of the conducting tape and the producing elements of the flocs image from the interactions of the electron beam with atoms at various magnification within the sample before and after treatment respectively.

The characteristics of the produced wastewater have been presented in Table 1. In Figure 5, when the coagulation reaction occurs during treatment, the positive charge nature of the polymer coagulants help the particles bind together, or coagulate (this process is sometimes also called flocculation) [31] as shown in Figure 5(a). The larger particles, or floc, are heavy and quickly settle to the bottom of the beakers (sedimentation) (see Figure 5(a) and Figure 5(b)). A change in the charge circulation in the top of the treated samples from suspended floc to settled water conditions may indicate that the particles are not settling and are distinctly different than the settled ones and may be less amenable to filtration (see Figure 5(a)) [32].

The generated wastewater has a $\mathrm{pH}$ value similar to that of raw water samples and contains about $10 \%$ of iron in dry mass. This is as a result of the poly ferric sulfate coagulant used during the dewatering process. From Figure 6(c) and Figure 6(d), with the combination of PAC and PA, the presence of the poly ferric sulfate content in the wastewater contributes to the bonding characteristics of 


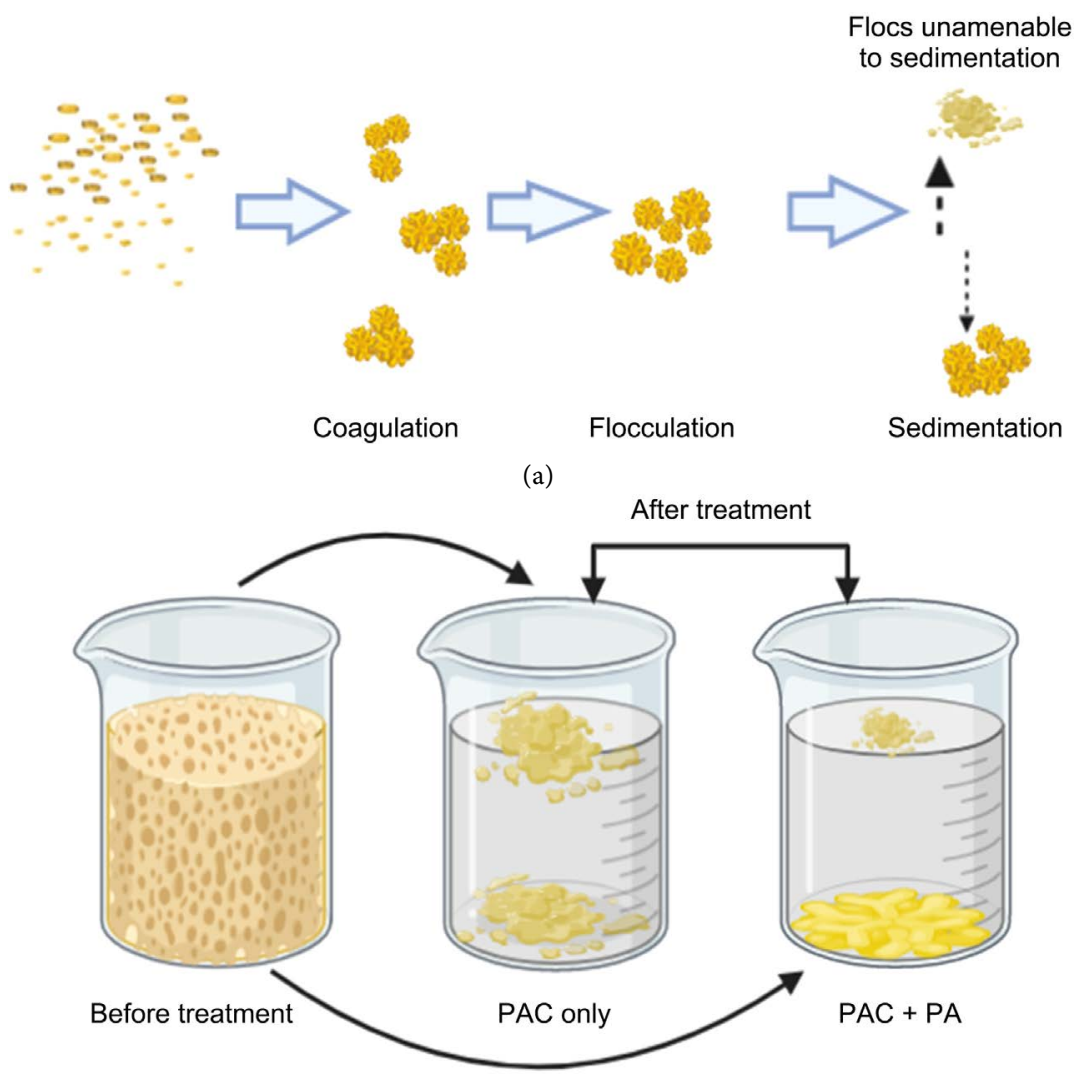

(b)

Figure 5. Flocs settlement behaviors.

the flocs produced [11] [33]. The charge density of the PAC coagulant also influence the charge neutralization during the treatment processes [20]. PAC treatment produces flocs that are more efficient in re-aggregating due to higher collision efficiency possibly as a result of more effective charge [32]. The non-treated flocs of the wastewater in Figure 6(a) and Figure 6(b) show no distinct shape or form when view in both low and high resolution. This is as a result of the colloidal matter which scatters and thus prevents its bonding [10] [23]. Furthermore, the fast mix time has a great impact on floc formation during the slow mix phase [28] [34]. In general, fast mixing for a time shorter than the optimum yields higher residual turbidity and larger flocs.

\subsection{Linked Cost}

During the collection of sludge samples, no potential on-site study for reducing effluent load by optimizing the wastewater treatment was investigated. In situ tests can be used for quantifying the impact of improvement measures and for identifying optimization potential [9]. As such, the effects of a change on the COD loading reduction cannot be determined. No cost was involved in the purchase of sludge sample, sludge disposal, and wastewater fee. The treatment cost of produced water can vary dramatically, based on the calculation method used and selected water quality parameters [35]. 


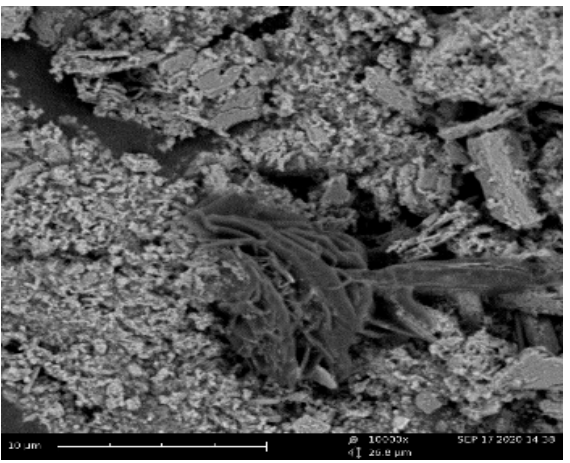

(a)

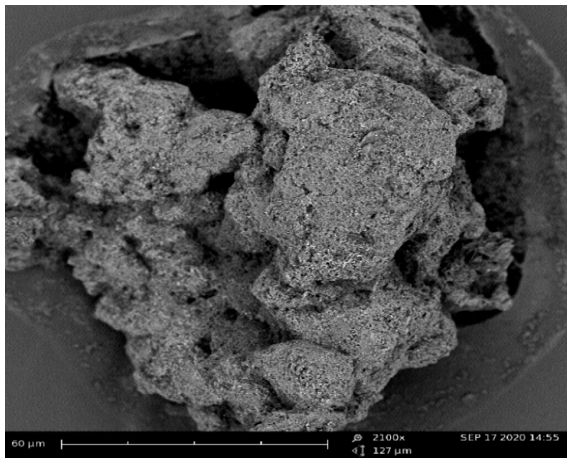

(c)

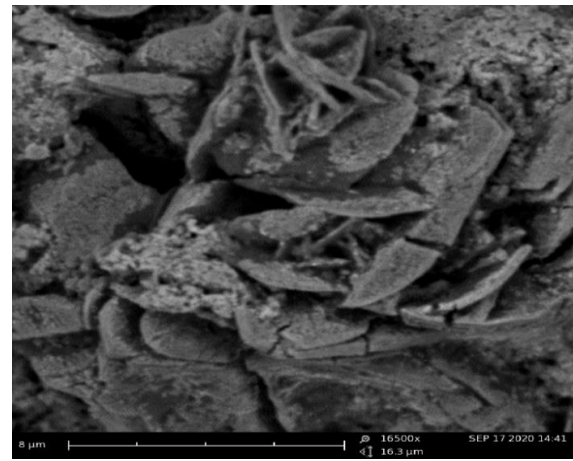

(b)

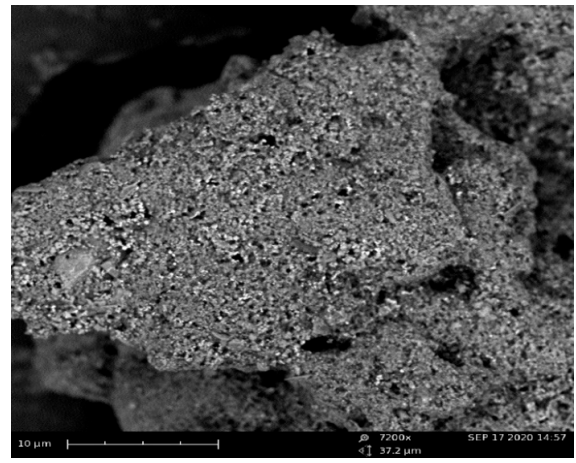

(d)

Figure 6. SEM images of the produced dried flocs (a) wastewater in high resolution, (b) wastewater in low resolution, (c) treated wastewater with $3.5 \mathrm{ml} \mathrm{PAC}$ and $50 \mathrm{ppm}$ PA in high resolution and (d) treated wastewater with $3.5 \mathrm{ml} \mathrm{PAC}$ and $50 \mathrm{ppm}$ PA in low resolution.

However, with the insurgence of the coronavirus outbreak which has halt a lot of economic activities in key import and export markets around the world, it could be very difficult to get efficient treatment cost of chemicals on wastewater treatment. This is as a result of the nose-dive from the chemicals producing industries that saw a decline in values throughout the pandemic period. Currently, no major manufacturers have announced turnarounds. However, reasonable cost based on current available data of chemicals is presented (See Table 3). As a result, the total operating cost analysis of the coagulation process was not carried out, as prices may hike when travelled restrictions are lifted in major manufacturing industries. In order to evaluate the actual operating cost for the COD and turbidity reduction by optimization of coagulation condition, the process must be operated for nearly one months, based on the extracted optimum coagulation conditions [36]. Current prices from Weifang Zhongqing Fine Chemical Co., Ltd (a Chinese company) is given in Table 3.

From an economic point of view of the linked cost presented in Table 3, PAC is the preferred coagulant which can be aided by PA, because it is possible for these coagulants to lower the concentration of the COD indicator by $80.6 \%$. In many cases when using PAC, post-treatment $\mathrm{pH}$ adjustment using an alkali is not required, this will thereby reduce the overall capital cost of the plant as well 
Table 3. Linked cost.

\begin{tabular}{ccccc}
\hline Coagulants & Unit & Cost USD & $\begin{array}{c}\text { Acid-Base } \\
\text { Property }\end{array}$ & $\begin{array}{c}\text { Environmental } \\
\text { Protection }\end{array}$ \\
\hline $\begin{array}{c}\text { Poly aluminum } \\
\text { chloride }\end{array}$ & Metric/Ton & $255-289 /$ Ton & $\begin{array}{c}\text { Alkaline surface } \\
\text { disposal agent }\end{array}$ & Yes \\
$\begin{array}{c}\text { Polymer } \\
\text { polyacrylamide }\end{array}$ & Metric/Ton & $255-289 /$ Ton & $\begin{array}{c}\text { Alkaline surface } \\
\text { disposal agent }\end{array}$ & Yes \\
\hline
\end{tabular}

Note: $1 \mathrm{RMB}=0.15 \mathrm{USD}=0.13 \mathrm{EUR}$ (As of October 2020 current exchange rate).

as improving operator service and reducing maintenance requirements [23]. It is important to note that the value of the COD parameter is strictly determined by the Environment Protection Agency in China, and for the bigger pollution loads the company will pay fees by reducing COD which is expected of them [9]. The continuous application of different coagulants to determine better treatment proficiencies and cost-effectiveness is a precondition for workable coagulation pre-treatment methods [16].

\section{Conclusions}

The study was applied to the analysis of cost-effective removal of COD in wastewater treatment. The disposal of this parameter into the environmental and natural water systems is a serious concern because it contains pollutants which when disposed of the environment are a serious health concern. Coagulation is generally a routine process in drinking water treatment plant as well as in wastewater treatment plant, as it reduces the repulsive potential of colloidal particles and help promote the combination of suspended solids that results in the formation of settable flocs that can be separated by another conventional treatment process such as sedimentation and filtration. The present study also found out that coagulation treatment is subtle to sensitive treatment factors such as the nature of turbidity producing substances like COD, turbidity levels, the type and doses of coagulant used, the $\mathrm{pH}$, and other factors such as hydrodynamic that promote the contact among colloidal particles.

However, based on demonstrated technological and economic benefits, PAC and PA seem to be the most promising for COD and turbidity removal, $\mathrm{pH}$, and temperature control in the wastewater industry due to their relatively high efficiency at lower costs. Results also demonstrated that the coagulation process can assure COD and turbidity removal from low, medium, and high turbid wastewater effectively. It was concluded that;

- The two selected coagulants demonstrated that the coagulation process could be applied as an onsite pre-treatment before other treatment methods for the removal of COD and turbidity in the sludge wastewater. The combination of PAC and PA was found to show better removal efficiency in COD as well as turbidity. PAC and PA were good at $80.6 \%$ COD reduction and show a decrease in turbidity of 181 NTU. The combination of these coagulants showed 
better flocs cohesion which can be useful for bulk disposal.

- Poly aluminum chloride coagulant can be advantageous over other traditional coagulants either in a low or high-temperature condition as it shows removal efficiency of $70.8 \%$ COD reduction when it is applied without other coagulant aid. This further explains the hydrolyzed sates of PAC of which temperature and $\mathrm{pH}$ have less effect during the treatment process. The selection of suitable $\mathrm{pH}$ and temperature has little significance on treatment efficiency as the coagulants used had shown an efficient reduction of all selected parameters i.e. COD, and turbidity while dosing of these coagulants.

- The results of the current study can be used as baseline data for onsite pre-treatment of wastewater treatment which uses poly aluminum chloride and poly ammonia as coagulants and flocculants.

\section{Acknowledgements}

This work is financially funded by Shanghai Fujie Environmental Protection Company.

\section{Conflict of Interests}

The authors declare no potential conflict of interest that could have appeared to influence the work reported in this paper.

\section{References}

[1] Rathilal, E.K.T. (2015) Application of Organic Coagulants in Water and Wastewater Treatment. Journal of Organic Chemistry, 8, 2-19.

[2] Bouranene, S., Sedira, N., Fievet, P. and Attia, N. (2015) Treatment of Paint Wastewater by Coagulation Process. Filtration + Separation, 52, 42-45. https://doi.org/10.1016/S0015-1882(15)30184-1

[3] Collivignarelli, M., Abbà, A., Benigna, I., Sorlini, S. and Torretta, V. (2017) Overview of the Main Disinfection Processes for Wastewater and Drinking Water Treatment Plants. Sustainability, 10, 86. https://doi.org/10.3390/su10010086

[4] Rodrigues, C.S.D., Boaventura, R.A.R. and Madeira, L.M. (2014) Technical and Economic Feasibility of Polyester Dyeing Wastewater Treatment by Coagulation/Flocculation and Fenton's Oxidation. Environmental Technology, 35, 1307-1319. https://doi.org/10.1080/09593330.2013.866983

[5] Valery, F., Kurenkov, H.-G.H. and Lobanov, F.I. (2002) Application of Polyacrylamide Flocculants for Water Treatment. Chemistry and Computational Simulations. Butlerov Communications, 3, 31-40.

[6] Grehs, B.W.N., Lopes, A.R., Moreira, N.F.F., Fernandes, T., Linton, M.A.O., Silva, A.M.T., et al. (2019) Removal of Microorganisms and Antibiotic Resistance Genes from Treated Urban Wastewater: A Comparison between Aluminium Sulphate and Tannin Coagulants. Water Research, 166, 115056. https://doi.org/10.1016/j.watres.2019.115056

[7] Tang, X.M., Zheng, H.L., Teng, H.K., Sun, Y.J., Guo, J.S., Xie W.Y., Yang, Q.Q. and Chen, W. (2014) Chemical Coagulation Process for the Removal of Heavy Metals from Water: A Review. Desalination and Water Treatment, 57, 1733-1748. https://doi.org/10.1080/19443994.2014.977959 
[8] Ashrafi, O., Yerushalmi, L. and Haghighat, F. (2015) Wastewater Treatment in the Pulp-and-Paper Industry: A Review of Treatment Processes and the Associated Greenhouse Gas Emission. Journal of Environmental Management, 158, 146-157. https://doi.org/10.1016/j.jenvman.2015.05.010

[9] Boguniewicz-Zablocka, J., Klosok-Bazan, I., Naddeo, V. and Mozejko, C.A. (2020) Cost-Effective Removal of COD in the Pre-Treatment of Wastewater from the Paper Industry. Water Science and Technology, 81, 1345-1353. https://doi.org/10.2166/wst.2019.328

[10] Wong, S.S., Teng, T.T., Ahmad, A.L., Zuhairi, A. and Najafpour, G. (2006) Treatment of Pulp and Paper Mill Wastewater by Polyacrylamide (PAM) in Polymer Induced Flocculation. Journal of Hazardous Materials, 135, 378-388. https://doi.org/10.1016/j.jhazmat.2005.11.076

[11] Ahmad, T., Ahmad, K., Ahad, A. and Alam, M. (2016) Characterization of Water Treatment Sludge and Its Reuse as Coagulant. Journal of Environmental Management, 182, 606-611.https://doi.org/10.1016/j.jenvman.2016.08.010

[12] Harnadek, C., Guilford, N. and Edwards, E. (2015) Chemical Oxygen Demand Analysis of Anaerobic Digester Contents. STEM Fellowship Journal, 1, 2-5. https://doi.org/10.17975/sfj-2015-008

[13] Rana, S. and Suresh, S. (2017) Comparison of Different Coagulants for Reduction of COD from Textile Industry Wastewater. Materials Today. Proceedings, 4, 567-574. https://doi.org/10.1016/j.matpr.2017.01.058

[14] Sahu, O.P. and Chaudhari, P.K. (2013) Review on Chemical Treatment of Industrial Waste Water. Journal of Applied Sciences and Environmental Management, 17, 241-257. https://doi.org/10.4314/jasem.v17i2.8

[15] Farajnezhad, H. and Gharbani, P. (2012) Coagulation Treatment of Wastewater in Petroleum Industry Using Poly Aluminum Chloride and Ferric Chloride. International Journal of Research and Reviews in Applied Sciences, 13, 306-310.

[16] Dotto, J., Fagundes-Klen, M.R., Veit, M.T., Palácio, S.M. and Bergamasco R. (2019) Performance of Different Coagulants in the Coagulation/Flocculation Process of Textile Wastewater. Journal of Cleaner Production, 208, 656-665. https://doi.org/10.1016/j.jclepro.2018.10.112

[17] Zand, A.D. and Hoveidi, H. (2015) Comparing Aluminium Sulfate and Poly-Aluminium Chloride (PAC) Performance in Turbidity Removal from Synthetic Water. Journal of Applied Biotechnology Report, 2, 288-292.

[18] Baghvand, A., Zand, A.D., Mehrdadi, N. and Karbassi, A. (2010) Optimizing Coagulation Process for Low to High Turbidity Waters Using Aluminum and Iron Salts. American Journal of Environmental Sciences, 6, 442-448. https://doi.org/10.3844/ajessp.2010.442.448

[19] Bu, F., Gao, B.Y., Shen, X., Wang, W.Y. and Yue, Q.Y. (2019) The Combination of Coagulation and Ozonation as a Pre-Treatment of Ultrafiltration in Water Treatment. Chemosphere, 231, 349-356.

https://doi.org/10.1016/j.chemosphere.2019.05.154

[20] Wang, X., Tang, X., Feng, P., Li, X., Zhao, C., Chen, W. and Zheng, H. (2017) A Novel Preparation Method of Polyaluminum Chloride/Polyacrylamide Composite Coagulant: Composition and Characteristic. Journal of Applied Polymer Science, 134, 44500. https://doi.org/10.1002/app.44500

[21] Bantcheva, I.G. (2001) Study on the Factors Affecting Coagulation and Flocculation in Treatment of Industrial Effluents. Transactions on Ecology and the Environment, 48, 156-162. 
[22] Dąbrowska, L. (2016) Removal of Organic Matter from Surface Water Using Coagulants with Various Basicity. Journal of Ecological Engineering, 17, 66-72. https://doi.org/10.12911/22998993/63307

[23] Gebbie, P. (2001) Using Polyaluminum Coagulants in Water Treatment. 64th Annual Water Industry Engineers and Operators' Conference, Bendigo, 5-6 September 2001, 39-47.

[24] Zhang, P., Hahn, H.H. and Hoffmann, E. (2003) Different Behavior of Iron (III) and Aluminum(III) Salts to Coagulate Silica Particle Suspension. Acta Hydrochimica et Hydrobiologica, 31, 145-151.

https://doi.org/10.1002/aheh.200300483

[25] Zhai, J., Huang, Z.J., Hasibur Rahaman, Md., Li, Y., Mei, L.Y., Ma, H.P., Hu, X.B., Xiao, H.W., Luo, Z.Y. and Wang, K.P. (2016) Comparison of Coagulation Pretreatment of Produced Water from Natural Gas Well by Polyaluminium Chloride and Polyferric Sulphate Coagulants. Environmental Technology, 38, 1200-1210. https://doi.org/10.1080/09593330.2016.1217937

[26] Al Momani, F.A. and Örmeci, B. (2014) Measurement of Polyacrylamide Polymers in Water and Wastewater Using an In-Line UV-Vis Spectrophotometer. Journal of Environmental Chemical Engineering, 2, 765-772.

https://doi.org/10.1016/j.jece.2014.02.015

[27] Kolade, D.M. (2016) Review Paper on Industrial Wastewater Treatment Processes. University of Nigeria, Nsukka.

[28] BinAhmed, S., Ayoub, G., Al-Hindi, M. and Azizi, F. (2014) The Effect of Fast Mixing Conditions on the Coagulation-Flocculation Process of Highly Turbid Suspensions Using Liquid Bittern Coagulant. Desalination and Water Treatment, 53, 3388-3396. https://doi.org/10.1080/19443994.2014.933043

[29] Robbins, R. (2015) Scanning Electron Microscope Operation: Zeiss Supra-40. The University of Texas at Dallas, Dallas.

[30] Irfan, M., Butt, T., Imtiaz, N., Abbas, N., Ahmad Khan, R. and Shafique, A. (2017) The Removal of COD, TSS and Colour of Black Liquor by Coagulation-Flocculation Process at Optimized pH, Settling and Dosing Rate. Arabian Journal of Chemistry, 10, S2307-S2318. https://doi.org/10.1016/j.arabjc.2013.08.007

[31] Peterson, H.G.W.R.E. (2001) Settling Time for Particles of Various Diameters, Rural Drinking Water and Waterborne Illness. Maintaining Drinking Water Quality, Lessons from the Prairies and Beyond, Proceedings of the 9 th National Conference on Drinking Water, Regina, 16-18 May 2000, 1-6.

[32] McCurdy, K., Carlson, K. and Dean, G. (2004) Floc Morphology and Cyclic Shearing Recovery: Comparison of Alum and Polyaluminum Chloride Coagulants. Water Research, 38, 486-494. https://doi.org/10.1016/j.watres.2003.10.005

[33] Nair, A.T. and Ahammed, M.M. (2015) The Reuse of Water Treatment Sludge as a Coagulant for Post-Treatment of UASB Reactor Treating Urban Wastewater. Journal of Cleaner Production, 96, 272-281.

https://doi.org/10.1016/j.jclepro.2013.12.037

[34] Kan, C.C., Huang, C.P. and Pan, J.R. (2002) Coagulation of High Turbidity Water: The Effects of Rapid Mixing. Journal of Water Supply: Research and Technology, 51, 77-85. https://doi.org/10.2166/aqua.2002.0007

[35] Dai, X.D., Fang, J., Li, L., Dong, Y. and Zhang, J.H. (2019) Enhancement of COD Removal from Oilfield Produced Wastewater by Combination of Advanced Oxidation, Adsorption and Ultrafiltration. International Journal of Environmental Re- 
search and Public Health, 16, 3223. https://doi.org/10.3390/ijerph16173223

[36] Yoo, S.S. (2018) Operating Cost Reduction of In-Line Coagulation/Ultrafiltration Membrane Process Attributed to Coagulation Condition Optimization for Irreversible Fouling Control. Water, 10, 1076. https://doi.org/10.3390/w10081076 